\title{
BRASIL: O OLHAR DE UM ESTRANGEIRO E A EDUCAÇÃO
}

\author{
Luciéli Sodré de Moura ${ }^{1}$ \\ Maria Aparecida Nunes Azzolin² \\ Valdo Hermes de Lima Barcelos ${ }^{3}$
}

\begin{abstract}
Resumo: Este artigo conta a história de um imigrante senegalês Aliou Badara Gningue, imigrante do Senegal, com 27 anos, que fala francês e wolof (língua nativa de Senegal), foi alfabetizado em árabe e está começando a construir seu conhecimento em português, aluno da Educação de Jovens e Adultos, do Colégio Estadual Cristóvão Pereira, que relata em sua fala o amor por esse país chamado Brasil e pela cidade de Santiago que está localizada a $470 \mathrm{Km}$ da capital do Rio Grande do Sul. Ao nos depararmos com a história de Aliou, percebemos que estas pessoas estão a quilômetros de distância das pessoas amadas, distante não só do afeto e aconchego do lar, mas distante dos cheiros e gostos de sua terra, sozinho num mundo diferente... língua diferente, uma cultura totalmente diferente... Na bagagem o medo do desconhecido, incertezas, insegurança e sonhos, muitos sonhos e com a esperança de uma vida melhor...sonhos de voltar à casa com condições melhores para poder ajudar suas famílias Em Santiago Aliou diz que encontrou uma família, que o acolheu como filho; sente saudade de casa, mas esta é compensada pelo carinho que é tratado e diz que "o Brasil tem povo muito bom, tem chuva, tem sol e principalmente tem trabalho". Buscamos mostrar como este imigrante interpreta o Brasil, como foi acolhido, seus anseios, dificuldades e principalmente o papel da educação no processo de adaptação no novo país.
\end{abstract}

Palavras-chave: Imigração; Educação; Interculturalidade; Cultura

\section{BRAZIL: THE LOOKING AT AN ALIEN AND EDUCATION}

Astract: This article tells the story of a Senegalese immigrant Aliou Badara Gningue, a 27-year-old Senegalese immigrant who speaks French and Wolof (a native language of Senegal), was literate in Arabic and is beginning to build his knowledge in Portuguese, a student of Education of Young People and Adults, of the State College Cristóvão Pereira, who reports in his speech the love for this country called Brazil and the city of Santiago that is located $470 \mathrm{~km}$ from the capital of Rio Grande do Sul. When we come across the story of Aliou, we realize that these people are miles away from loved ones, not only from the affection and

\footnotetext{
${ }^{1}$ Psicóloga, Professora Convidada PROIPE/CE/UFSM. Email: lucielidemoura@ hotmail.com.

${ }^{2}$ Doutoranda em Educação UFSM, Professora Convidada PROIPE/CE/UFSM, Professora do Estado RS. Emai: cidaazzolin@gmail.com.

${ }^{3}$ Professor Titular PPGE UFSM, vbarcelos@terra.com.br.
} 
warmth of the home, but far from the smells and tastes of their land, alone in a different world ... different language, a totally different culture .. In the baggage the fear of the unknown, uncertainties, insecurity and dreams, many dreams and with the hope of a better life ... dreams of returning to the house with better conditions to be able to help their families In Santiago Aliou says that he found a family, who welcomed him as his son; she misses home, but this is compensated by the affection that is treated and says that "Brazil has very good people, it has rain, it has sunshine and mainly it has work". We seek to show how this immigrant interprets Brazil, how it was welcomed, its longings, difficulties and especially the role of education in the process of adaptation in the new country.

Keywords: Immigration; Education; Interculturality; Culture

\section{Iniciando o conversar....}

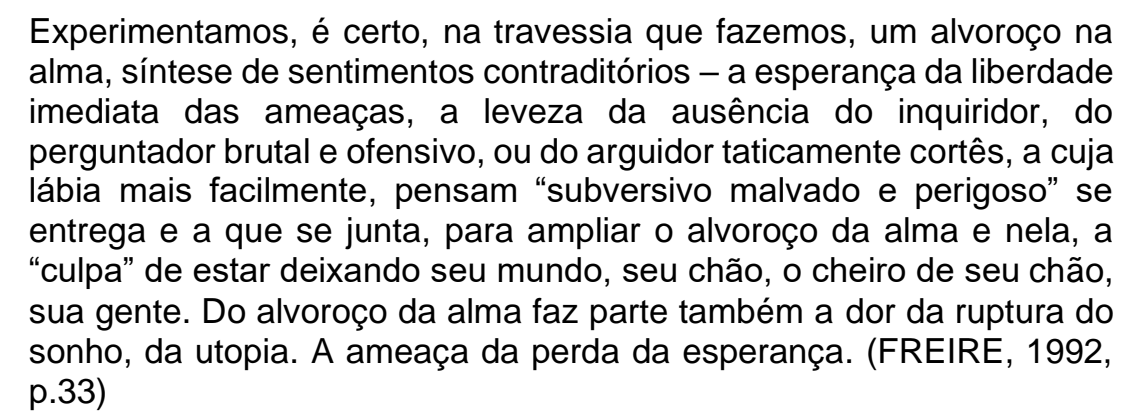

Mares de distância, quilômetros das pessoas amadas, distante não só do afeto e aconchego do lar, mas distante dos cheiros e gostos de sua terra. Sozinho num mundo diferente. língua diferente, uma cultura totalmente diferente na bagagem o medo do desconhecido, incertezas, insegurança e sonhos, muitos sonhos. Essa é a história de milhares de imigrantes vindo de diferentes países, com a esperança de uma vida melhor sonhos de voltar à casa com condições melhores para poder ajudar suas famílias...Sonhos que os movem....e que nos movem como educadoras e pesquisadoras....aprender em cada momento da existência. ter a oportunidade de melhorar a vida das pessoas que nos são caras. Esperança, não "na pura espera" (FREIRE, 1992, p.11), mas esperança que ancora a luta, a ação. Nesta busca por aprendizados encontramos o Aliou Badara Gningue, imigrante do Senegal, com 27 anos, que fala francês e wolof (língua nativa de Senegal), foi alfabetizado em árabe e está começando a construir seu conhecimento em português, aluno da totalidade 4 da Educação de Jovens e Adultos, do Colégio Estadual Cristóvão Pereira, que relata em sua fala o amor por 
esse país chamado Brasil e pela cidade de Santiago que está localizada a $470 \mathrm{Km}$ da capital do Rio Grande do Sul. Em Santiago Aliou diz que encontrou uma família, que o acolheu como filho; sente saudade de casa, mas esta é compensada pelo carinho que é tratado e diz que "o Brasil tem povo muito bom, tem chuva, tem sol e principalmente tem trabalho".

\section{Primeiros passos rumo ao desconhecido...}

Em uma conversa tranquila e informal perguntamos ao Aliou porque ele havia saído de Senegal e vindo para o Brasil, literalmente rumo ao desconhecido e ele com um sotaque gostoso de ouvir nos relata sua trajetória de vida: " "Minha vida tem uns complicado e outros que dá certo também, lá na África a vida é mais difícil, daí eu tenho uma família grande, não é rica, não tem muito dinheiro, porque na África não tem muito trabalho, falta muito trabalho, é muito difícil achar trabalho com carteira assinada, lá a gente tem famílias bem grande, mais ou menos de 30 pessoas, daí a gente precisa de trabalho para poder ajudar a família, é bem complicado, quando eu era criança, tinha dias que nem tinha comida para comer, mas agora graças a Deus está melhorando as coisas, eu tenho muitos amigos, e tenho muitas saudades deles, porque fazem 3 anos que estou aqui no Brasil, da mãe e da família também, sinto muita saudade. Mas é bom. Na minha cidade a gente trabalha mais na agricultura, mas a agricultura é muito difícil, porque não chove muito, não tem muita água, porque só chove 3 meses, depois para a chuva, por isso a gente não tem muita água, como aqui no Brasil. Tem comércio também, graças a Deus, fazem 5 anos tem uma empresa que trabalha na minério lá, graças a Deus tem gente que mora na minha cidade que trabalha lá também, antes de vir pro Brasil, ficava na minha casa 3 meses, 4 meses só dormir, não tem trabalho, não ganho nada, daí tu vê tua família precisando de dinheiro, precisando de dinheiro para comprar comida, para pagar luz e pagar um monte de coisas e não tem como você um homem com força para trabalhar e não tem, tu fica todo dia sem trabalhar, todo dia chegando conta e tu sem trabalhar, não tem como.". Com essa fala percebemos a dor de ter que sair e deixar para trás sua vida, seus sonhos e reconstruir uma nova vida e novos sonhos com apenas a fé e a esperança. 


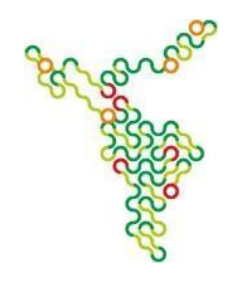

Esperança de encontrar algo melhor, algo que possibilite melhorar a vida das pessoas que ficaram, amigos e família. Paulo Freire, quando foi exilado, em setembro de 1964, partindo para a Bolívia, foi arrancado cruelmente de suas raízes, ele relata sua dor ao deixar seu país no seguinte trecho da obra "À sombra desta mangueira" (1995):

\begin{abstract}
Sofrer o exílio é mais do que reconhecer sua realidade. É assumi-lo com toda a dor que isso significa, somente como o exilado ou exilada se prepara para a volta. Sofrer o exílio é assumir o trauma da ruptura que caracteriza a experiência de existir num contexto de empréstimo. Sofro o meu exílio ao lidar melhor com as dificuldades provocadas pela impossibilidade de voltar à minha origem; ao resolver as contradições entre o presente que vivo num espaço em que não vivi o passado, e o futuro a ser construído num espaço incerto. (FREIRE, 1995,51)
\end{abstract}

Este senegalês, foco da construção deste artigo, também devido ao contexto social que estava inserido teve que sair de seu chão, para conseguir condições melhores de vida, principalmente a alimentação diária, não só para si, mas também para a sua família. Aliou relata que o que Ihe conforta nos momentos de grande saudade de sua pátria e de sua família é saber que ao retornar para casa a família vai estar em melhores condições do que quando ele saiu, pois todo mês ele envia recursos que ganha vendendo produtos, como carteiras e capas de celular, no calçadão de Santiago. Aliou fala com muito carinho do Brasil, país que o acolheu, dizendo que chegou ao Acre como clandestino, ficou lá um mês e quinze dias esperando a documentação, mas depois veio para Bento Gonçalves e em duas semanas já estava trabalhando e afirma: "Não desisti de estar aqui, no Brasil tem gente muito boa, gente boa mesmo que ajuda os imigrantes. Eu gostei muito do Brasil". A possibilidade de poder ajudar sua família, de ser sujeito de sua história, de sentir-se cidadão, moveu e move este imigrante, ele deixa bem claro que há muitas dificuldades, mas o acolhimento por pessoas da comunidade faz com que estas dificuldades sejam menores.

Ao ser questionado sobre os motivos de buscar a alfabetização em português, visto que já era alfabetizado em árabe, Aliou expõem que "quando eu cheguei aqui no Brasil, tinha facebook, watts zap e tinha amigos no Brasil, mas não conseguia conversar com eles, quando entra no banco, no caixa eletrônico, 
não entendia a língua. Senão falar, ler e escrever o português fica difícil tudo. O português é muito difícil. $O$ francês é mais fácil para aprender. Aprendendo português posso tirar carteira de motorista, posso pegar um ônibus. Se eu estou estudando a vida fica muito melhor." Aliou buscou o conhecimento por necessidade de comunicar-se, de sentir-se pertencente a esta comunidade. Por não falar a língua, a conversações com as pessoas de Santiago tornava-se cada vez mais limitadas. A linguagem existia a partir de gestos, ou seja da corporeidade, mas extremamente limitada. Para Humberto Maturana (2014, p. 165- 168)

\begin{abstract}
Nós, seres humanos, existimos na linguagem, e nossa experiência como seres humanos acontece na linguagem num fluir de coordenações consensuais de coordenações consensuais de ações que produzimos na linguagem. Os objetos, a consciência, a autorreflexão, o self, a natureza, a realidade, e assim por diante, tudo o que nós, seres humanos, fazemos e somos acontece na linguagem como distinções ou como explicações na linguagem do nosso estar na linguagem. (...) A vida nos acontece, a experiência nos acontece, os mundos que vivemos nos acontecem ao trazê-los à mão em nossas explicações".
\end{abstract}

Entendemos Cultura como "um conjunto de coisas, de instituições, de ideias e imagem através das quais uma determinada sociedade se manifesta e se institui" (Barcelos 2016, p.159), a partir disso Aliou realizou comparações entre o Brasil e Senegal: "a cultura do Brasil é bem diferente de Senegal, e aqui a cultura gaúcha é muito, muito diferente, as comida são diferente. Lá não tem essas comidas que tem aqui. Aqui tem muitas carnes, lá a gente come mais peixe e come arroz com peixe e legume. O churrasco do gaúcho é muito bom. Já provei o chimarrão. Lá a gente toma café e chá. O chimarrão a gente tem que aprender a tomar. Em Senegal a maior parte das pessoas são mulçumanos, mas tem católicos, mas todos vivem em paz, se um católico comemora as suas festas, faz um prato e leva para o vizinho que é mulçumano e o mulçumano faz a mesma coisa. Existe o respeito, ninguém vai lá e diz que sua religião não é boa. Aqui no Brasil tem uma presidenta, lá no Senegal o homem é o chefe da casa, a mulher pode trabalhar fora, mas é o marido que compra comida e roupas, a mulher ajuda nas despesas da casa só se quiser, porque é obrigação do homem sustentar a casa, a mulher 
pode deixar seu dinheiro guardado, aqui a mulher manda também, mas lá se a mulher não quer casar, não vai a polícia forçar, tem famílias que ainda escolhem a esposa e o esposo para os filhos, o homem se puder sustentar pode ter até 4 esposas, mas as mulheres lutam por igualdade como no Brasil". Para Maturana (apud Barcelos, 2016, p. 159)

Começa a aparecer uma cultura quando permanecem através das gerações certos modos relacionais de viver e conviver. Visto que humanos vivem e convivem na linguagem e no conversar, com o termo cultura passa-se a conotar certo modo de conversar, o qual passa a se fixar transgeracionalmente em redes de conversações. Uma cultura se especifica através de um modo ou de um certo conjunto de modos de conversar. E seria possível notar que nos modos de conversar se mantém certos modos condutuais. Estes como condutas relacionais e sentires relacionais íntimos que permanecem, e com eles se configura a cultura.

Aliou absorveu certos hábitos da cultura brasileira, mais especificamente gaúcha, como degustar um bom churrasco aos domingos, tomar chimarrão, mas aspectos relacionados à sua religião mulçumana, como fazer as cinco orações diárias ele preserva, mesmo não havendo uma mesquita para ele frequentar, bem como não comer carne suína. Percebemos que ele se adaptou muito bem, incorporando alguns hábitos, mas não deixando de lado os aspectos que ele julga mais importantes como sua humildade, sua forma de encarar a vida e sua fé.

O viajante Aliou, durante seu percurso passou por diversas culturas, mas sem esquecer a cultura de sua terra natal, desta forma foi integrando novas culturas a sua história. Conforme Berry (1997) esta forma de agregar culturas nomeasse de aculturação, sendo uma forma de preservar os

valores de sua cultura, incorporando com os valores da nova comunidade, como meio de manter contato e sentir-se pertencente a essa nova sociedade.

Um dos fatores para a importância do processo de aculturação e integração de culturas é a comunicação linguística, pois esta é considerada como um meio de integração social e de percepção de fazer parte do grupo. Aliou em sua fala remete-se a estas questões, pois ele relata que "a dificuldade de quando cheguei no Brasil foi a fala e entender o que se falava, eu precisava mandar dinheiro para a minha família em Senegal, mas no início não conseguia sozinho pois não compreendia o português". Foi movido por esta dificuldade que ele resolveu 


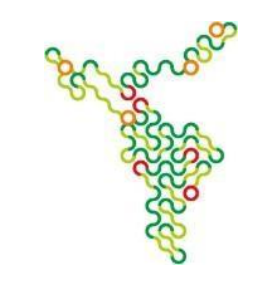

alfabetizar-se em português.

Este imigrante nos demostra em cada fala um exemplo de persistência, resiliência e esperança, diz que não foi fácil chegar aqui, que foi a coisa mais difícil que fez na vida, 8 dias de viagem, que trabalhou mais de 10 anos para juntar 0 dinheiro suficiente para comprar as passagens, movido só pela esperança de encontrar condições de trabalhar e ajudar sua família, sonha em fazer o curso superior de Medicina, não para ser rico, como acontece no Brasil, mas pra poder voltar para sua terra e ajudar as pessoas, principalmente as mulheres, porque a taxa de mortalidade na hora do parto é muito grande. Aliou fala em esperança, em sonho, com um profundo amor por sua terra natal, por sua família e por sua nova terra, a terra da esperança, chamada de Brasil.

\section{Aliou: acolhido e acolhendo Santiago}

O processo da construção de identidade se estabelece a partir das relações do corpo e da consciência com o mundo, tornando-se um sujeito com suas singularidades pertencente à um contexto social, onde se movimenta, constrói e produz sua história. Desta forma a construção do sujeito se baseia no passado, mas em virtude de um futuro, Aliou nesta travessia entre Senegal e Brasil busca um futuro melhor para si e sua família, que permaneceu em sua terra natal, passou por condições e situações que o caracterizaram como homem e que fazem parte de sua identidade. Conforme Sarter (1984) o homem é caracterizado pela superação das situações ao qual vivencia em direção ao novo, a transformação, implicando em realizações e recusa.

O sujeito é um ser significante ao qual pode dar sentido para suas vivencia no mundo, tornando-se assim singular num espaço coletivo, Maheirie (2002) ressalta que o processo de construção é realizado no coletivo, onde singularidades se (des)encontram, construindo além da sua

história, como também a do outro, da mesma forma que o outro também tem participação na sua história.

Este entrelaço entre singularidades e coletividade está presente na vida de Aliou quando ele relata o momento ao qual ele recebeu uma notificação em julho 
de 2017, que o mesmo deveria retirar suas mercadorias no prazo de 48 horas do local de comercialização, mas não havia especificações de onde ele poderia fazer a venda. Faziam dois anos que Aliou trabalhava no mesmo local, na segunda quadra do calçadão de Santiago, e é de onde ele retira o dinheiro para seu sustento e para mandar à sua família em Senegal. Neste momento ele teve apoio do coletivo, onde uma advogada que tornou- se sua amiga, postou no Facebook e a comunidade santiaguense prestou forte solidariedade buscando respostas das autoridades competentes para solucionar a questão, a situação foi solucionada. Da mesma forma que o coletivo fez e faz parte da história e identidade de Aliou, Aliou faz parte da história do coletivo.

Desta forma Maheirie reflete que;

Todo processo de construção deste sujeito é realizado no coletivo e, por ser uma obra de autoria coletiva, em maior ou em menor medida, a história pode lhe escapar. Assim, inserido neste cenário de múltiplas singularidades que se entrecruzam, ele realiza a sua história e a dos outros, na mesma medida em que é realizado por ela, sendo, por isso, produto e produtor, simultaneamente. (Maheirie, p.7,2002)

O processo de construção de identidade vai sendo tecida durante toda a vida e esta sempre em constantes mutações, pois o sujeito transita por diferentes cenários coletivos, onde histórias se entrecruzam. É uma viajem em que durante o percurso do viajante, há (des) encontros com seus semelhantes, marcas deixadas, aprendizagens, traduzindo em significações e assim se entrelaçando, fazendo parte da história do sujeito e de sua identidade. Um ser que constrói sua identidade através do convívio com o outro, mas que diferenciase dos outros pelas suas singularidades e peculiaridades. Além de fazer parte desta sociedade, Aliou também sentiu-se acolhido pelas pessoas, para a psicanalise o acolhimento é acolher a demanda, o sofrimento, é aceitar, ajudar e colocar-se a disposição do "paciente", aqui no caso de Aliou ele relata que o "Brasil o acolheu, pois ele tem uma nova família, que foi quem the deu abrigo, tem muitos amigos", no momento em que ele necessitava de apoio, obteve inclusive de pessoas que não o conheciam pessoalmente, com isso ele relata sou profundo agradecimento a Santiago, terra que ele tem muito carinho e demonstrou 
isso ao solicitar à direção da escola, que no desfile de 07 de setembro, gostaria de desfilar com a bandeira de Santiago (foto em anexo 1), assim desfilou lindamente com a roupa típica de Senegal e orgulhosamente carregando a bandeira de sua nova terra, terra que o acolheu e foi acolhida por ele.

Em cada fala Aliou deixa claro a forma que foi acolhido em Santiago, que "nós não moramos muito tempo em uma mesma cidade, mas na primeira semana que cheguei aqui, as pessoas me davam roupas, o que comer, conversavam comigo, é uma cidade bem bom, então parei aqui, recebi muito carinho, que não esperava, sabia que era uma cidade muito boa, mas quando aconteceu a questão da prefeitura, não imaginava receber todo esse carinho, a casa onde eu moro a mulher me trata como filho." Aliou como imigrante sente-se acolhido e parte desta nova sociedade. Assim permite usufruir de um sentimento de pertencimento de duas culturas, sem afetar a sua identidade cultural.

Aliou com seu jeito humilde, sereno de falar, sua visão positiva, sem reclamar das agruras da vida, nos ensina a perceber o belo e valorizar o que é essencial na vida, ou seja os bons relacionamentos, as amizades, o afeto que é dado e recebido. Saint-Exupéry, no livro "O pequeno Príncipe" escreve que somos eternamente responsáveis pelo que cativamos, e assim nos sentimos em relação a Aliou, nos sentimos responsáveis, porque ele nos cativou e nos ensinou várias lições nas conversas que tivemos, aprendemos a ter esperança, a não desistir mesmo que as condições sejam adversas, a lutar por nossos sonhos, mas principalmente a amar o outro, a amar seu chão, sendo ele o que nascemos ou o que acolhemos e fomos acolhidos.

\section{Referências}

BARCELOS, Valdo. MADERS, Sandra. PASINI, Giovani. Cenas e cenários interculturais - Pensando epistemologias a partir do Sul. Santa Maria: Editora e Gráfica Caxias, 2016.

FREIRE, Paulo. À sombra desta mangueira. São Paulo: Editora Olho d'Água, 1995.

\section{Pedagogia da Esperança - Um reencontro com a Pedagogia do}


oprimido. $5^{\text {a }}$ ed. Rio de Janeiro: Paz e Terra, 1992

MAHEIRIE, Katia. Constituição do sujeito, subjetividade e identidade. Interações, vol. VII, núm. 13, jan-jun, 2002, pp. 31-44, Universidade São Marcos, São Paulo, Brasil. Disponível em<http://www.redalyc.org/articulo.oa?id=35401303 > acessado em 05/09/2019.

MATURANA, Humberto; MAGRO, Cristina (org); PAREDES, Victor (org). Cognição, Ciência e vida cotidiana. Belo Horizonte: Editora UFMG. 2014

SARTRE, Jean Paul. Questão de Método. In: Os Pensadores. São Paulo: Abril Cultural, 1984.

SOUZA, Cátia; GONÇALVES, Gabriela. Imigrantes e Sociedades de Acolhimento: percepções e realidades no caso de Portugual. Psicologia \& Sociedade, 2015, 27(3), pp. 548-557. Disponível em <http://dx.doi.org/10.1590/1807-03102015v27n3p548> acessado em 05/09/2019. 